\title{
A CANÇÃO "VOZES DA SECA" DE LUIZ GONZAGA: VOZES DE PROTESTO SOB UMA PERSPECTIVA DA ANÁLISE DO DISCURSO
}

\author{
THE SONG “VOZES DA SECA” BY LUIZ GONZAGA: VOICES OF \\ PROTEST FROM A FRENCH DISCOURSE ANALYSIS PERSPECTIVE
}

\author{
Sandro Luis de Sousa ${ }^{1}$ \\ Instituto Federal do Rio Grande do Norte
}

\section{RESUMO}

O trabalho estuda a canção Vozes da Seca dos autores nordestinos, Luiz Gonzaga e Zedantas pelos pressupostos teóricos da Análise de Discurso (AD) de linha francesa. Pretende-se demonstrar que a materialidade linguística objeto de estudo apresenta características contrastantes face ao estereótipo de sujeito nordestino pobre, alienado político e eterno dependente dos favores dos "sulistas". Neste artigo, a análise tem como propósito compreender como o texto da composição é tecido, criando relações entre a língua e aspectos sócio-históricos que imprimem ao discurso características próprias de dizeres expressos e implícitos na canção ora analisada.

PALAVRAS-CHAVE: Análise do Discurso. Luiz Gonzaga. Aspectos sócio-históricos.

\begin{abstract}
This work proposes studying the song "Vozes da Seca" (voices of the drought) by composers Luiz Gonzaga e Zedantas under the theoretical assumptions of French Discourse Analysis. It aims to demonstrate that this linguistic materiality as an object of study presents contrasting features to the stereotyped Brazilian nordestino subject: pauper, politically alienated, and eternal dependent of southern people's favors. The analysis wants to understand how the song lyrics is woven, creating relationships between language and sociohistorical aspects which give the discourse its own characteristics of expressed and implicit meanings in the examined song.
\end{abstract}

KEYWORDS: French Discourse Analysis; Luiz Gonzaga; sociohistorical aspects.

"Se só houvesse submissão, não haveria produção de novos sentidos".

\section{INTRODUÇÃO}

Rosário Gregolin

Neste artigo propomos estudar a canção Vozes da Seca dos autores nordestinos, Luiz Gonzaga e Zedantas ${ }^{2}$, tendo como pressupostos teóricos norteadores a Análise de Discurso de linha francesa (doravante, AD). Para tanto, entende-se como necessário, em primeiro lugar, fazer uma breve incursão sobre alguns conceitos básicos da $\mathrm{AD}$, bem como sobre a caracterização do sujeito-intérprete da referida canção e das condições de produção do ambiente sócio-histórico onde a mesma foi concebida. Pretende-se demonstrar que a materialidade linguística objeto de estudo apresenta, de forma incomum, características de contraponto ao disseminado estereótipo

\footnotetext{
1 Professor do IFRN, Campus Natal-Central. Doutorando em Linguagens e Cultura pela UFPB. Email: sandro.sousa@ifrn.edu.br.

${ }^{2}$ Mantivemos aqui a forma como Zedantas gostava de assinar seu nome em suas composições, segundo observação de Ferreti (2012, p. 9).
} 
de sujeito nordestino pobre, pedinte de esmola, ignorante, conformado, alienado político e eterno dependente dos favores dos "povos do sul".

A análise não tem como propósito metodológico precípuo a organização linguísticoestrutural do texto como um "produto" pronto e acabado, mas compreender como esse texto é tecido, criando nós, laços e relações entre a língua e aspectos sócio-históricos que imprimem ao discurso características próprias de dizeres expressos e implícitos na canção analisada. Desse modo, é da mediação entre o dispositivo escolhido, a fundamentação teórica subjacente e o objetivo proposto, que o texto exsurge como unidade de análise privilegiada da Análise do Discurso.

\section{Considerações iniciais sobre a análise do discurso}

Há diversas orientações para o estudo da linguagem. Duas delas talvez sejam as mais conhecidas: a forma de analisar a língua em sua suas características imanentes, que evidencia a separação dicotômica entre língua e fala, reservando a esta última um papel secundário e que remonta aos estudos estruturalistas inspirados em Saussure, ou a aplicação de regras, conforme uma prescrição advinda da gramática normativa que persegue o "bom" uso da língua enquanto sistema estrutural-funcional. Não obstante essas duas vertentes, o recente domínio da AD emerge como contraponto às duas orientações retrocitadas, pondo em evidência as relações que se estabelecem entre os sujeitos produtores de discurso e o "produto" por eles produzidos. Desse modo, segundo Orlandi, (2013, p. 16) a Análise do Discurso

não trabalha com a língua enquanto um sistema abstrato, mas a língua no mundo, com maneiras de significar, com homens falando, considerando a produção de sentidos enquanto parte de suas vidas, seja enquanto sujeitos seja enquanto membros de uma determinada forma de sociedade.

Os homens estão, portanto, inseridos em ambientações específicas, próprias de espaços geográficos e histórico-sociais nos quais as relações interpessoais se engendram, fazendo surgir diversos discursos com diferentes sentidos e distintas interpretações do que é dito e do que não é dito explicitamente pela palavra, conforme as condições de produção desses discursos.

A palavra, já o sabemos, é considerada o fenômeno ideológico por excelência (BAKHTIN, 1988, p. 36), posto que é produto da interação verbal. Com inspiração em Bakhtin, Brandão (1995, p. 10), assevera que, por ser dialógica por natureza, a palavra se transforma em arena de luta de vozes que, situadas em diferentes posições, querem ser ouvidas por outras vozes. $\mathrm{Na}$ acepção aqui usada, o vocábulo vozes permite fazer remissões às noções de dialogismo e polifonia em Análise do Discurso. A primeira, explicam-nos Charaudeau e Maingueneau (2014, p. 160), refere-se às relações que todo enunciado mantém com os enunciados já produzidos, assim como com os enunciados futuros que poderão ser produzidos, enquanto a segunda reporta-se à presença de pontos de vista diferentes veiculados pelos textos. Pensar os indivíduos nesse contexto implica pensá-los enquanto sujeitos ideologicamente marcados.

Consoante Orlandi (2013, p. 17), a AD trabalha a relação língua-discurso-ideologia, partindo da ideia de que a materialidade específica da ideologia é o discurso e a materialidade específica do discurso é a língua. Para aquela autora, a ideologia é considerada efeito da relação necessária do sujeito com a língua e com a história para que exista sentido. Nesse cenário, o indivíduo é assujeitado ou interpelado como sujeito ideológico, no sentido em que cada um é conduzido, sem se dar conta, e tem a impressão de estar exercendo sua livre vontade (PÊCHEUX; FUCHS, p. 165-166), produzindo seu próprio modo de dizer, mas que na verdade este decorre do funcionamento da instância ideológica, situando a posição do sujeito em uma determinada classe social. Como corolário dessa vinculação a uma conjuntura sócio-histórica dada, emerge a formação discursiva, isto é, aquilo que determina o que pode e deve ser dito numa formação ideológica dada (ORLANDI, 2013, p. 43). Neste aspecto, é possível traçar uma 
referência à noção de interdição, uma vez que toda produção de discurso poder ser controlada. $\mathrm{Na}$ nossa sociedade, não se tem o direito de dizer tudo nem se pode falar de tudo em qualquer circunstância (FOUCAULT, 1989; p. 9).

Com esteio nessas características, a AD é descrita como uma disciplina de entremeio cujo quadro epistemológico reside, segundo Pêcheux (1997, p. 164), na articulação de três regiões do conhecimento científico, a saber:

1. o materialismo, como teoria das formações sociais e de suas transformações, compreendida aí a teoria das ideologias;

2. a linguística, como teoria dos mecanismo sintáticos e dos processos de enunciação ao mesmo tempo;

3. a teoria do discurso, como teoria da determinação histórica dos processos semânticos.

A junção desses três domínios deve ser também compreendida, ainda segundo Pêcheux, levando-se em consideração o fato de que é atravessada e articulada por uma teoria da subjetividade de natureza psicanalítica. Conforme se avulta, esse tripé fundador, composto de História-Língua-Sujeito, implica uma necessária inter-relação entre essas três regiões de conhecimento: Linguística, Marxismo (materialismo histórico) e Psicanálise.

Em uma releitura dessas disciplinas, a $\mathrm{AD}$ defende que a produção de discurso se estabelece considerando a historicidade da linguagem, a sua não transparência, e a noção de indivíduo transformado em sujeito descentralizado. Essa reconceptualização de sujeito, advinda da Psicanálise, é recepcionada pela $\mathrm{AD}$ que o entende como aquele que não é senhor de si mesmo, nem como um ser apriorístico ao discurso, pois o sujeito já nasce imerso nos diversos discursos que circulam na sociedade. Assim, o sujeito é entendido como sendo cindido, clivado, já que as formações discursivas são heterogêneas. Diante deste quadro epistemológico, tem-se que os discursos são lacunares. Tal como uma teia, o discurso é formado por nós e, ao mesmo, tempo, possui buracos, furos que lhe são constitutivos, que deixam escapar o real da língua, entendido como aquilo que não pode ser simbolizado totalmente na palavra e na escrita (FERREIRA, 2011). Segunda a autora, Pêcheux pensa o real da língua como um corpo - não biológico, não orgânico - atravessado de falhas, ou seja, submetido à irrupção da falta. $O$ real pode, desse modo, ser representado pelas falhas, pelos atos falhos, pelos lapsos e chistes. Dessa forma, a $\mathrm{AD}$ não se contenta com a inteligibilidade (sentido literal do enunciado) ou interpretação (sentido do co-texto e contexto de entorno) de um objeto simbólico. A AD vai além, buscando a sua compreensão. Dessarte, Orlandi (2013, p. 26) esclarece que

a Análise do Discurso visa a compreensão de como um objeto simbólico produz sentidos, como ele está investido de significância para e por sujeitos. Essa compreensão, por sua vez, implica em explicitar como o texto organiza os gestos de interpretação que relacionam sujeito e sentido. Produzem-se assim novas práticas de leitura.

Entende-se por objeto simbólico as materialidades significantes, tais como um texto, uma pintura, uma imagem, ou, como no caso aqui examinado, uma canção. Assim, uma materialidade concreta para a $\mathrm{AD}$ é a matéria de que é feita o discurso, uma vez que todo discurso tem uma forma. Em suma, a materialidade, em sua dimensão concreta, é uma forma de linguagem. Nas palavras de Gregolin (2011, p. 83), a multiplicidade de objetos de análise deriva da complexidade do conceito de discurso, já que envolve a linguagem, os sujeitos e as determinações sociais e históricas, por isso é que surge uma necessidade da articulação com outros saberes - tal qual a história, por exemplo - para dar conta dos objetos mobilizados pelos analistas.

Finalmente, não obstante essa diversidade de objetos, pode-se afirmar com Orlandi ( $o p$. cit.) que "o discurso é efeito de sentidos entre locutores".

\section{Contextualizando o ambiente do sujeito-autor Luiz Gonzaga}


Luiz Gonzaga nasceu ao pé da Serra do Araripe, em 13 de dezembro de 1912, na fazenda Caiçara, em Exu, município do oeste pernambucano, fronteira com o Crato, município cearense. Gonzaga cresceu nesse espaço, o Cariri pernambucano, participando de atividades agrícolas para ajudar a família ao mesmo tempo em que aprendia com o pai a tocar as primeiras notas ao acordeom. Era o ambiente de encontros com as pessoas nas feiras, de trabalho como ajudante do coronel Manuel Aires de Alencar e, mais tarde, dos bailes animados pela sanfona de oito baixos de Gonzaga. Ambiente, então, de valiosas interações linguísticas e sócio-culturais naquela região pernambucana. Rebento de família pertencente à classe social baixa exuense, o segundo de um grupo de nove filhos, conforme relatou o próprio Gonzaga: "fui o segundo dos nove, o primeiro sendo Joca. Depois, em anos sucessivos ou espaçados, foram chegando Geni (Efigênia), Severino, José, Raimunda (Muniz), Francisca, Socorro e Aloísio” (SINVAL SÁ, 2012, p. 22).

Batizado Luiz Gonzaga do Nascimento na matriz de Exu em 5 de janeiro de 1913, o Rei do Baião ganhou esse nome por sugestão do então padre, José Fernandes de Medeiros. Porque nascera no dia de Santa Luzia, deveria se chamar Luiz, já que era homem, Gonzaga porque era o complemento do nome do santo Luiz Gonzaga, e, por fim, Nascimento em virtude de dezembro ser o mês de nascimento do menino Jesus. Interessante registrar que foi o único com nome diferente dos demais irmãos, como atesta a pesquisadora Dominique Dreyfus (2012, p. 31).

Luiz Gonzaga apresentou logo cedo certa musicalidade, acompanhando o pai nas festas e tocando sanfona de oito baixos. Aos dezessete anos, fugiu de casa para o Ceará, após levar uma surra da mãe, que soubera que o filho havia desafiado - armado com uma faca - o pai de Nazinha, garota com quem namorava às escondidas e pretendia casar-se. Ao chegar ao Rio de Janeiro em 1939, já possuía uma sanfona maior e passou a frequentar programas de calouros na Radio Nacional. Alcançou o sucesso. Conquistou o Rio de Janeiro. E, como consequência, o Brasil. Por justo merecimento, tornou-se conhecido como o Rei do Baião. A mudança para o sudeste proporcionou a Gonzaga o contato com o grande centro produtor do mercado fonográfico. Como lembra Laraia (2013, p. 46), não basta a natureza criar gênios, isto acontece com frequência; entretanto, faz-se necessário que coloque ao alcance desses indivíduos o material que lhes permita exercer toda sua criatividade de uma forma revolucionária.

Luiz Gonzaga tinha consciência que seu grande público o acompanhava aonde fosse, principalmente os migrantes residentes no Rio e São Paulo. O seu idioleto ${ }^{3}$ era predominantemente o do falar nordestino, mesmo que tivesse tido a oportunidade de conviver com advogado, médico - profissões de seus principais parceiros -, músicos, compositores e empresários. As músicas de Luiz Gonzaga exaltavam, principalmente, o Nordeste, seus ritmos, sua língua, seu povo e suas tradições culturais. Segundo Albuquerque Jr. (2011, p. 178),

Luiz Gonzaga assume a identidade de "voz do Nordeste" que quer fazer sua realidade chegar ao Sul e ao governo. Sua música "quer tornar o Nordestino conhecido em todo país”, chamando a atenção para seus problemas, despertando o interesse por suas tradições e "cantando suas coisas positivas".

\subsection{O Entorno sócio-histórico: a seca de 1953}

Em 1953, o país vivia o governo do presidente Getúlio Vargas, eleito democraticamente em 1950. Antes dessa fase democrática, Vargas já havia governado o Brasil por quinze anos ininterruptos, quando assumiu o poder logo após a revolução de 1930 (1930-1937), e, depois, quando instituiu a ditadura do Estado Novo (1937-1945). Segundo Beloch et al (2010), o segundo período do governo varguista foi marcado pela retomada de uma orientação nacionalista cuja expressão maior foi a luta para a implantação do monopólio estatal sobre o petróleo, com a criação da Petrobrás. É nessa conjuntura que, entre os anos 1951-1953, o nordeste brasileiro

\footnotetext{
${ }^{3}$ Língua tal como é observada no uso particular de um indivíduo.
} 
enfrentou uma seca bastante prolongada, mobilizando os estados do sul em campanhas de ajuda aos nordestinos.

É historicamente emblemático o caso do município de Surubim, em Pernambuco, onde aproximadamente 1.500 pessoas, desesperadas, se aglomeraram para saquear o comércio local. $\mathrm{O}$ saque só foi evitado pela intervenção do pároco local, padre Ferreira Lima, que arrecadou cestas básicas dos comerciantes da cidade para doar ao povo faminto.

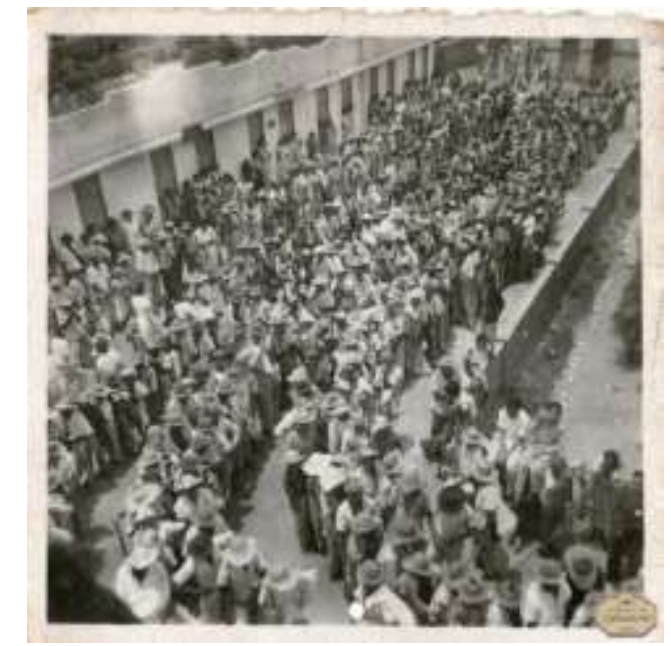

Figura 01: Aglomeração dos flagelados da seca de 1953, em Surubim/PE.

Fonte: <http://www.isurubim.net/2012/11/imagens-impressionantesa-invasao-dos.html>

Inserido nesse contexto dramático, o objeto simbólico aqui referenciado - a canção Vozes da Seca - foi composto por Luiz Gonzaga e Zedantas, seu parceiro musical em várias músicas de sucesso na carreira do Rei do Baião. Na verdade, cerca de $86 \%$ das músicas gravadas por Luiz Gonzaga, entre 1949 e 1957, são de composições com o médico Zedantas, conforme informa Ferreti (2012, p. 19).

\section{Os Discursos sobre o Nordeste e os nordestinos}

Laraia, (2013, p. 45) referindo-se ao homem em geral, diz que este

é o resultado do meio cultural em que foi socializado. Ele é o herdeiro de um longo processo acumulativo, que reflete o conhecimento e a experiência adquiridas pelas numerosas gerações que o antecederam. A manipulação adequada e criativa desse patrimônio cultural permite as inovações e as invenções.

No que concerne ao contexto cultural nordestino, por ser uma região menos industrializada e economicamente mais frágil, frequentemente o Nordeste é retratado como espaço inferior, lugar de penúria e miserabilidade, e o homem nordestino é visto como pessoa mal-informada, alheia aos condicionamentos sócio-históricos que suscitam as adversidades que afligem sua vida. Esse quadro cria uma espécie de arquivo cultural de nordeste subdesenvolvido e ignorante que é replicado em textos, músicas e poesias. Desse modo, Lucena (2006, p. 3.) pondera que

este contexto sócio-histórico constrói uma memória coletiva que é repassada de geração a geração e constrói formações discursivas peculiares a essa realidade. Formações estas que carregam consigo valores, mitos, crenças os quais se arquivam no saber de uma comunidade e se condensa por práticas sociais ressonantes em vozes sociais capazes de identificarem sujeitos ideologicamente marcados por este processo histórico. 
Não obstante a situação apresentada, atualmente é possível verificar a existência de um tipo de discurso diametralmente oposto: que promove o Nordeste como espaço paradisíaco, com riquezas naturais e pujante em diversidade cultural. Por exemplo, Lucena (2012, p. 17) verificou práticas discursivas em folhetos turísticos que reconstroem a imagem do Nordeste não como um lugar de atraso, decadência e problema social brasileiro, mas como territorialização constituída de raízes sócio-histórico-culturais capazes de construir uma memória integralizadora de triunfos de uma identidade brasileira.

Dessa forma, tem-se que os discursos podem confrontar-se à memória coletiva que é transferida de geração a geração de uma imagem de nordeste pobre onde os nordestinos são indivíduos sem instrução, intrinsecamente subordinados e conformados com a sua situação sócio-econômica. Adiante, analisamos um discurso cuja materialidade discursiva é uma canção que já se contrapunha, anos atrás, à situação de subserviência do homem nordestino.

\title{
4. Vozes da seca, vozes de protesto
}

Na música popular do nordeste, feita nas décadas de 40 e 50, não é raro encontrar letras que retratem uma memória sócio-histórica de nordestinos desvalidos, muitas vezes, conformados com a situação de penúria causada "exclusivamente", para muitos, pela baixa pluviometria da região. Entretanto, é igualmente possível encontrar canções que questionam a situação de dependência econômica e de falta de investimento na região. Passemos, pois, à análise do texto da canção Vozes da Seca:

\author{
Vozes da Seca \\ (Luiz Gonzaga/Zedantas)
}

Seu dotô ${ }^{4}$ os nordestino têm muita gratidão

Pelo auxílio dos sulista nessa seca do sertão

Mas dotô uma esmola a um homem qui é são

Ou lhe mata de vergonha ou vicia o cidadão

É por isso que pidimo proteção a vosmicê

Home pur nóis escuído para as rédias do pudê

Pois doutô dos vinte estado temos oito sem chovê

Veja bem, quase a metade do Brasil tá sem cume

Dê serviço a nosso povo, encha os rio de barrage

Dê cumida a preço bom, não esqueça a açudage

Livre assim nóis da ismola, que no fim dessa estiage

Lhe pagamo inté os juru sem gastá nossa corage

Se o doutô fizer assim salva o povo do sertão

Quando um dia a chuva vim, que riqueza pra nação!

Nunca mais nóis pensa em seca, vai dá tudo nesse chão

Como vê nosso distino mecê tem nas vossa mãos

O enunciador dirige-se a seu interlocutor utilizando um tratamento respeitoso duplo, "seu dotô", o que indica uma relação assimétrica entre classes sociais, numa alusão de subordinação do administrado que desejar dialogar com a figura do administrador, o então presidente da República Getúlio Vargas. À medida que o "diálogo" avança, a formalidade diminui: "seu dotô" > vosmicê $>$ mecê. Desse modo, o efeito de sentido é de que o tratamento começa solene e avança para um tom menos formal, em busca de uma aproximação entre classes para a justificar os pedidos que virão em seguida.

\footnotetext{
${ }^{4}$ Utiliza-se a transcrição grafemática do texto, mantendo-se as formas linguísticas das palavras e expressões tais quais foram usadas na canção.
} 
Não obstante o reconhecimento da situação de carência causada pela seca e a gratidão pela ajuda recebida pelos "sulistas", os sentidos instaurados a partir do texto remetem a um sujeito que se posiciona e tem ciência de que a resolução para o seu estado de privação material não está na doação de ajuda material. Cascudo (2011[1974], p. 25) afirmava que o "mendigo, humilhado e suspeito é um produto urbano". O efeito de sentido é de que o homem nordestino é sadio, reconhecidamente trabalhador e não precisa de "esmolas". O enunciador se insurge contra essa "ajuda" que traz consequência negativa dupla: dar esmola ao nordestino economicamente ativo pode ser extremamente vergonhoso e desmoralizante, condenando-o à ociosidade e à humilhante dependência socioeconômica dos estados do sul. Essa insurgência, porém, não revela uma atitude revolucionária, já que se aceita receber em troca do trabalho realizado, o que remonta à ideologia capitalista de compra e venda da força de trabalho. O sentido que emerge do discurso do sujeito-autor questiona a ideia de identidade exterior nordestina estereotipada: o vadio que ganha sem trabalhar. Neste ponto, esse efeito de sentido se coaduna com a opinião de Albuquerque Jr. (2011, p. 38) que defende existir no interior dessa identidade uma diferença fundante, uma batalha, uma luta, que é preciso ser explicitada.

Nessa luta, o sujeito demonstra ter também consciência de que o indivíduo responsável pela administração do país foi eleito democraticamente (home pur nóis escuído para as rédias do pudê) e, portanto, é lícito reivindicar uma solução definitiva para o problema de convivência com os efeitos danosos da seca. É significativo o uso da metáfora "rédeas do poder" que traz o efeito de sentido de que o governante pode controlar seu povo por intermédio de instrumentos eminentemente usados para dominar animais irracionais, suscitando uma memória discursiva acerca de uma identidade nordestina de subordinação alimária que inclui, dentre outras construções metafóricas, expressões como "voto de cabresto" e "curral eleitoral".

Por outro lado, o enunciador ${ }^{5}$ sabe que o cenário de estiagem apresentado alcança quase todo o país e se posiciona quanto a essa situação, sugerindo ações que vão desde a implantação de infra-estrutura (encha os rio de barrage, não esquę̧a a açudage) à política econômica (dê serviço a nosso povo, dê cumida a preşo bom). As medidas apontadas pelo sujeito revelam uma memória discursiva de investimento em áreas estratégicas que podem levar ao fim desse estado de dependência da solidariedade de seus compatriotas, libertando-os, assim, da submissão econômica (Livre assim nóis da ismola) dos estados "do sul".

O sujeito enunciador fala na primeira pessoa do plural, colocando-se como representante de um grupo, porta-voz de um dialogismo legitimado pela ideologia do sistema democrático, que tem no lema "o governo do povo, pelo povo e para o povo" a sua maior representatividade. Por isso, o emprego das palavras "Brasil" como "nação", composta por "vinte estados" - e não apenas por alguns - cujos "cidadão", inclusive o "home por nóis escuído", devem desempenhar deveres que a todos são atribuídos democraticamente, sem exclusão. Ademais, o sujeito deixa revelar que compreende, como parte integrante do exercício da cidadania, a apresentação de proposições com o intuito de incentivar melhorias nas condições sócio-econômicas de uma população sofrida. Em suma, o protesto propositivo é dialógico e polifônico, pertinente, convergindo para um objetivo comum: a resolução de problemas sócio-históricos dos nordestinos, de forma definitiva.

Outro sentido instaurado é o do sujeito enunciador que assegura o pagamento do investimento a ser feito na região, vez que os nordestinos pagariam de bom grado o montante do crédito liberado, o que lhes garantiria não ter mais que depender de esmolas nem ver a sua dignidade abalada (lhe pagamo inté os juru sem gastar nossa corage). Tal cenário revela valores ideológicos integrados no dizer do enunciador: o homem nordestino precisa de crédito, mas não dará calote, posto que ter coragem para trabalhar é um dos seus melhores atributos.

A certeza de que a saída para os problemas apresentados é uma política econômica inclusiva, que trará soluções definitivas para o sertão, põe em relevo que o sujeito não é simplório, alheio às causas das condições adversas que afligem a extensão areal onde vive ( $S e$ o

${ }^{5}$ O termo enunciador se refere à perspectiva que o "eu" assume no discurso. 
doutô fižr assim salva o povo do sertão). Mediante os pedidos para realização de obras estruturantes, o sujeito demonstra compreender que não se pode eliminar o fenômeno da seca, mas deve-se aprender a conviver com ela. O destino dos nordestinos, que é, em última análise, o de todos os brasileiros, depende apenas das ações governamentais daqueles que detêm o poder, privilegiando a superação das diferenças regionais historicamente criadas (Como vê nosso distino mercê tem nas vossa mãos), mormente por intermédio de investimentos em obras que desmontem a "indústria da seca" no Nordeste, prática bastante fomentada entre políticos fisiologistas.

Por fim, é lícito afirmar que o sujeito deixa revelar, pelo discurso, que é cônscio de que as relações de poder interferem naquilo que os nordestinos são naquele momento sócio-histórico, questionando o que se poderia fazer para que a situação fosse diferente do que ela é.

\section{CONSIDERAÇÕES FINAIS}

A análise da canção "vozes da seca", ancorada nos pressupostos teóricos apresentados sob a perspectiva da Análise do Discurso, permite fazer algumas inferências conclusivas. Passemos a expô-las.

A canção permite entrever vários efeitos de sentidos que emergem da historicidade do texto que trata da visão do enunciador sobre a situação de seca e as condições sócio-econômicas dos nordestinos. O discurso faz revelar uma formação discursiva social-democrática que traz consigo valores que defendem uma criação do Nordeste como espaço sócio-histórico livre das dependências pluviométrica (natural) e econômica (cultural) do centro-sul brasileiro. O sujeito enunciador apresenta-se, assim, propositivo. O enunciador mostra-se, efetivamente, como representante legítimo de um conjunto de vozes, vozes de uma coletividade cuja identidade interior se opõe - embora de forma não panfletária - contra a estereotipada identidade exterior nordestina: maltrapilho pedinte, resignado com a sua situação sócio-econômica.

Foi possível verificar sentidos que emergem do discurso enquanto reveladores de uma memória discursiva de falta de investimentos econômicos nos estados nordestinos que os relegam à categoria de espaços subdesenvolvidos e esquecidos (dê serviço a nosso povo, encha os rio de barrage, dê cumida a preço bom, não esqueça a açudage, livre assim nóis da ismola, quase a metade do Brasil tá sem cume). Não obstante seu passado ditatorial, Getúlio ficou conhecido como o "pai dos pobres". Daí, o efeito de sentido de somente aquele que promoveu direitos sociais e trabalhistas, poderia fazer as verdadeiras mudanças na vida dos nordestinos pobres. Evidenciamos também efeitos de sentido retratados na expressão metafórica reveladora de um Nordeste submisso (rédias do pudê), evocando o dialogismo com outras construções metafóricas, como "voto de cabresto" e "curral eleitoral".

O discurso do enunciador é permeado de reivindicações e propostas, apontando as possíveis soluções para o problema de convivência com a estiagem prolongada. As representações do homem nordestino na canção "vozes da seca" desvela ainda sentidos sobre um sujeito que cobra responsabilidade de quem detém o poder-dever institucional de investir na região para eliminar as discrepâncias sócio-econômicas historicamente construídas.

Por fim, o texto, como espaço significante do discurso instaurado, permitiu entrever um sujeito-autor que não se harmoniza com a visão estereotipada de canções que cantam um nordeste somente de resignação "romântica" frente à situação de dificuldades que atravessa por causa da seca prolongada. O enunciador possibilitou revelar efeitos de sentidos no texto, a partir de várias vozes: vozes da seca, vozes de protesto que, sob o ponto de vista da Análise do Discurso, busca incessantemente compreender os diferentes processos de significação em função de sua historicidade. Concluindo, retomamos a epígrafe de um de nossos interlocutores e que abre este estudo: "se só houvesse submissão, não haveria produção de novos sentidos".

\section{REFERÊNCIAS BIBLIOGRÁFICAS}

ALBUQUERQUE Jr., Durval Muniz de. A Invenção do Nordeste e Outras Artes. 5. ed. Editora Cortez: São Paulo, 2011. 
BAKHTIN, Mikhail. Marxismo e Filosofia da Linguagem. 4. ed. São Paulo: Editora HUCITEC, 1988.

BELOCH, Israel et al. Getúlio Vargas. In: Dicionário Histórico-Biográfico Brasileiro DHBB. Centro de Pesquisa e Documentação de História Contemporânea do Brasil da Fundação Getúlio Vargas. Disponível em: $<$ http://cpdoc.fgv.br/producao/dossies/JK/bio grafias/getulio_vargas>. Acesso em: 22 ago. 2104.

BRANDÃO, Helena H. Nagamine. Introdução à Análise do Discurso. 4. ed. Campinas/SP: Editora da Unicamp, 1995.

CASCUDO, Luís da Câmara. Religião no povo. 2 ed. São Paulo: Global, 2011 [1974].

CHARAUDEAU, Patrick; MAINGUENEAU, Dominique. Dicionário de Análise do Discurso. Coordenação da tradução Fabiana Komesu. 3. ed. 1. reimp. São Paulo: Ed. Contexto, 2014. Título original: Dictionnaire d' analyse du discours.

DREYFUS, Dominique. Vida do Viajante: a saga de Luiz Gonzaga. 3. ed. São Paulo: Ed. 34, 2012.

FERREIRA, Maria Cristina Leandro. O Lugar do Social e da Cultura numa Dimensão Discursiva. In: INDURSKY, Freda; MITTMAN, Solange; FERREIRA, Maria Cristina Leandro (Orgs.). Memória e História na/da Análise do Discurso. Campinas, SP: Mercado de letras, 2011.

FERRETTI. Mundicarmo. Na Batida do Baião, no Balanço do Forró: Zedantas e Luiz Gonzaga. Recife: Fundação Joaquim Nabuco, Ed. Massangana, 2012.

FOUCAULT, Michel. A Ordem do Discurso: aula inaugural no collège de France, pronunciada em 2 de dezembro de 1970. Tradução de Laura Fraga de Almeida Sampaio. 5. ed. São Paulo: Edições Loyola, 1989.

GREGOLIN, Maria do Rosário Valencise. Análise do Discurso e Semiologia: enfrentando discursividades contemporâneas. In: PIOVEZANI, Carlos; CURCINO, Luzmar. Discurso Semiologia e História. São Paulo: Claraluz, 2011.

Introdução à Análise de Discurso e à obra de Michel Foucault. Programa de PósGraduação em Comunicação, Cultura e Amazônia, UFPA. Grupo de Estudo Mediação, Discursos e Sociedades Amazônicas. Direção: Ivânia Neves. Belém: [s.d.]. Disponível em:<http://www.youtube.com/watch? v=EUwmCxB1Tp4>. Acesso em: 17. ago. 2014.

IMAGENS impressionantes: a invasão dos flagelos da seca em Surubim, 1953. iSurubim. Surubim/PE, 5 nov. 2012. Disponível em:< http://www.isurubim.net/2012/11/imagens-impres sionantesa-invasao-dos.html>. Acesso em: 22 ago. 2014.

LARAIA, Roque de Barros. Cultura: um conceito antropológico. 25. reimpr. Rio de Janeiro: Zahar, 2013.

LUCENA, Ivone Tavares de. Entre o Discurso, a História e a Cultura: a irrupção de um novo nordeste. In: LINS, Juarez Nogueira (Org.). Nos Domínios da Linguagem: entre discurso, literatura e linguística. João Pessoa: Editora Universitária de UFPB, 2012. 250 p. p. 15-32. 
Vozes que (Re)montam o Nordeste: uma trajetória histórico-cultural. Revista Língua, Linguística e Literatura: revista do Departamento de Letras Clássica e Vernáculas da UFPB. v. 4. n. 1. João Pessoa: Editora Universitária, 2006. 190 p.

ORLANDI, Eni P. Análise de Discurso: princípios e procedimentos. 11. ed. Campinas, SP: Pontes Editores, 2013.

PÊCHEUX, Michel; FUCHS, C. A Propósito da Análise Automática do Discurso: atualização e perspectivas (1975). C. In: GADET, Françoise.; HAK, Tony (Orgs.). Por uma Análise Automática do Discurso: uma introdução à obra de Michel Pêcheux. Tradução de Betânia S. Mariani et al. 3. ed. Campinas/SP: Editora da Unicamp, 1997.

SÁ, SINVAL. O Sanfoneiro do Riacho da Brígida: vida e andanças de Luiz Gonzaga - O Rei do Baião. 7. ed. Recife: Cepe, 2012.

Recebido em 12/02/2017

Aceito em 19/04/2017

Publicado em 17/05/2017 